\title{
Editorial
}

\section{Is Resilience in COVID-19, Its Lasting Legacy?}

\author{
Poonam Malhotra Kapoor ${ }^{1}$ \\ ${ }^{1}$ Department of Cardiac Anaesthesia, All India Institute of Medical \\ Sciences, New Delhi, India
}

J Card Crit Care:2020;4:73-74

The best response to disaster is resilience

- by Madeleine Albright U.S. Secretary of State

Short-term stress has a potential effect to lead to either long-term growth and thriving or to a prolonged stress injury. Either outcome is dependent on the culture, the infrastructure, and actions of the people. The chief key to attain posttraumatic growth is resilience in an individual and in the organization. ${ }^{1}$

According to World Health Organization, in their April 15, 2020, public statement, when the coronavirus pandemic, runs riot the human weakness within is to be avoided. ${ }^{2}$ This can be overcome by advising the public to follow a assiduous and conscientious lifestyle by adopting and patronizing a rigorous protocol of preventing large gatherings in prayers and social events; promote physical and social distancing, maintain hand hygiene, and respiratory etiquette; and maintain clean, sanitized environment by maintaining general hygiene and sanitation especially in places of public gatherings and personal use too ${ }^{2}$ ( Table 1, - Fig. 1).

\section{Masks and Personal Protective Equipment are Necessary Dressing to Combat the Virus}

As an anesthesiologist or intensivist, while working in the operating room/intensive care unit, all our procedures, giving drugs, use of monitors for patients' surveillance, and getting the patient on and off cardiopulmonary bypass, all require extreme fortitude, grit, self-determination, and a certain amount of obdurateness in following protocols and algorithms for patient safety. The COVID-19 pandemic with its camouflaging and sudden worsening pneumonia-like symptoms, wherein any amount of proning/ventilator and nonventilator therapies, may be of no use, is a challenge requiring us to be pliable and resilient or else there will be inner stress and health of the caregivers will suffer.

\footnotetext{
Address for correspondence

Poonam Malhotra Kapoor, MD, DNB, MNAMS, FIACTA (Hony),

FTEE ( Hony), FISCU (Hony),

Department of Cardiac Anaesthesia,

All India Institute of Medical

Sciences, Sri Aurobindo Marg,

Ansari Nagar, Ansari Nagar

East, New Delhi 110029, India

(e-mail: drpoonamaiims@gmail.com).
}

\section{Anesthesiologists and Intensivists are most Resilient in COVID-19 Pandemic}

In a pandemic crisis, a holistic approach entails, providing physical, emotional, and psychological needs to the workforce. This requires early on, before any pandemic, organization should work toward creating a resilient organization workforce, wherein the health care workers should continue to work but under an established plan to suspend or reduce nonessential task; during the pandemic emphasis embody the importance of visible and influential leadership.

All the above measures, like the measures enlisted for wearing a personal protective equipment ( - Fig. 2) for tracheal intubation of a COVID-19 positive patient require courage, sound knowledge, deftness, prayers, and a lot of mental resilience. The personnel involved for tracheal intubation need maximum courage and resilience-that inner discipline of knowing that what we are doing is correct, and a reassurance that it will not ever, harm us ${ }^{3}$ (-Fig. 2).

To perform without stress is the need of the hour. The COVID pandemic pressure is positively bringing forth many discoveries, all over the world. This pandemic with 18 different groups of drugs given as treatment, has over 94 clinical research trials opening up in March to April 2020 in the U.S. itself. But, the bottom line should be achieving success over the COVID without stress and thrombosis. Motivation and dynamic action are buzzwords of today's competitive world, but accepting the final outcome of hard work with calm, still mind, will enable us to think with clarity, and work intelligently, toward deriving a CORONA solution.

\section{Finding Kindness and Resilience during a Pandemic}

However, one thing that has struck me during this pandemic is how, through hardship, the positive aspects of human
DOI https://doi.org/ 10.1055/s-0040-1721181 ISSN 2457-0206.

published online November 2, 2020
(C) 2020. Official Publication of The Simulation Society (TSS), accredited by International Society of Cardiovascular Ultrasound (ISCU).

This is an open access article published by Thieme under the terms of the Creative Commons Attribution-NonDerivative-NonCommercial-License, permitting copying and reproduction so long as the original work is given appropriate credit. Contents may not be used for commercial purposes, or adapted, remixed, transformed or built upon. (https://creativecommons.org/licenses/by-nc-nd/4.0/)

Thieme Medical and Scientific Publishers Pvt. Ltd., A-12, 2nd Floor, Sector 2, Noida-201301 UP, India 
Table 1 WHO mitigation measures for physical gatherings

\begin{tabular}{|l|}
\hline Mitigation measures cover a variety of topics, including: \\
\hline - Understanding of the overview of the current COVID-19 \\
situation by event organizers
\end{tabular}

Abbreviation: WHO, World Health Organization.

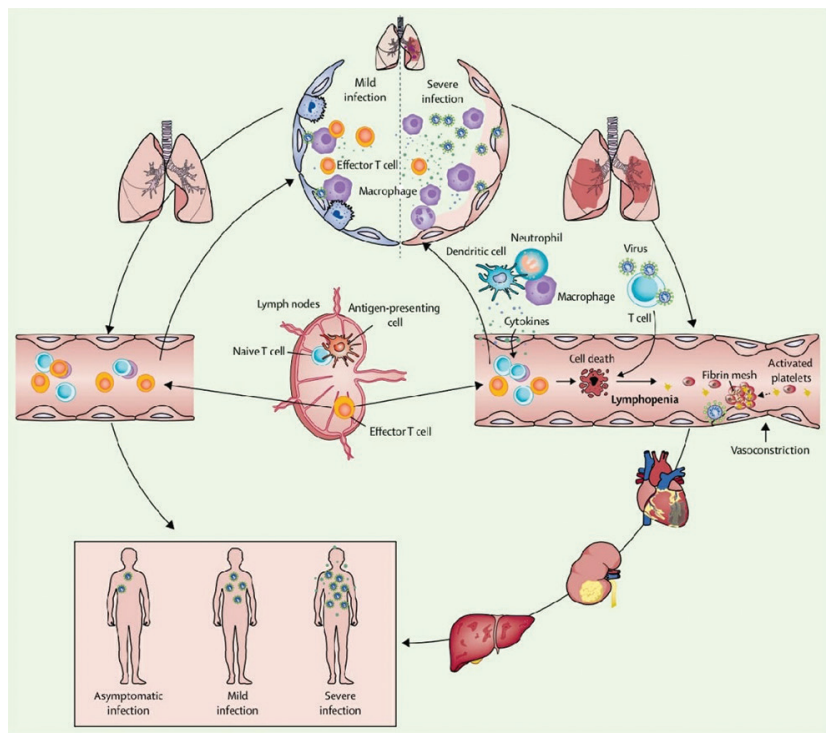

Fig. 1 The recovery from coronavirus follows a chain process.
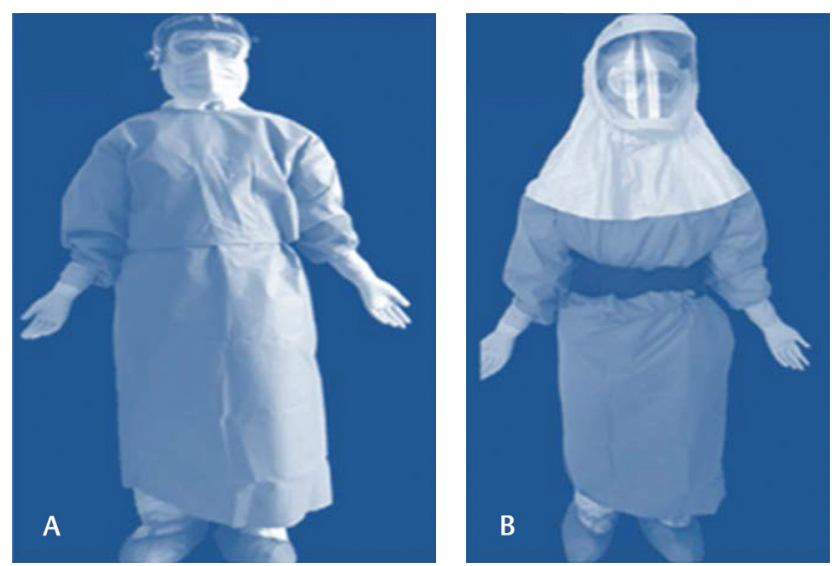

Fig. 2 Wearing a (A) personal protective equipment (PPE), or an (B) outer layer with a hood with a powered air-purifying respirator (PAPR), requires time and fortitude and to continue to work wearing it, requires immense resilience. Anesthesiologists have shown in this pandemic they have it most.

nature-kindness and resilience-shine through. It shows glimpses of hope in this challenging battle with the virus.

We have learned that we are in this pandemic for the long haul. It has now been months since the first case in December
2019. However, the fact that we find the strength to physically and mentally cope with this crisis speaks to our resilience.

"\#CORONA SOLUTIONS-WE CAN, WE WILL FIND THEM" is a BUZZWORD at JCCC-TSS College of Cardiac Critical Care fellowship and webinars in $2020 .{ }^{4}$ This special Part 2 of the COVID-19 e-supplement from some experts in corona solutions, help us to bring our readers different treatment strategies from gross to the subtlest. It is the subtle things like the mind, which is always working in the realm of the known. The intellect creativity-the "buddhi" in Indian scriptures-is always working in the right direction, in the unknown, goes and investigates through research, discovery, and invention. It does not know, but because of continuous right thinking and discrimination, it eventually, comes up with a solution. And so, will this universe with subtlest powerful minds in drugs and vaccine trials come up with a treatment, to this life-threatening COVID-19, 2020, pandemic. This, is in true essence, also the essence of the Bhagavad Gita which preaches "True Karma Yoga," where the mind is in its most productive and eternally satisfied framework has reiterated that "Perspective is an amazing art." ${ }^{5}$ The poetry from COVID survivors and warriors in the end of this issue, brings forth the resilience of the cardiac critical care intensivist overcoming this environmental trigger. The editorial by Kanchi Muralidhar and brief communication in the end which has been framed keeping the mental real in focus of the intensivist is a must read.

Let's try and keep things in perspective. Let's be smart, help each other out, and we will get through all of this. In the history of the world, there has never been a storm that lasted. Only resilience and perseverance helps wither all storms with grit, determination, and everlasting resilience. "This too, shall pass," should be our motto, adopted with resilience and humility, so that we all can camouflage and adopt the new norm, post-COVID, with flexibility and buoyancy. From surviving to thriving with resilience should be the lasting legacy the corona virus leaves behind in each one of us. We require ego-resilience and influential leadership to adapt to this COVID pandemic which is transformative in nature. ${ }^{6}$

\section{Conflict of Interest}

None declared.

\section{References}

1 Fuchs A, Abegglen S, Berger-Estilita J, Greif R, Eigenmann H. Distress and resilience of healthcare professionals during the COVID-19pandemic(DARVID): study protocolforamixed-methods research project. BMJ Open 2020;10(7):e039832

2 How to use WHO risk assessment and mitigation checklist for Mass Gatherings in the context of COVID-19. Interim Guidance March 20, 2020

3 Yao W, Wang T, Jiang B, et al; collaborators. Emergency tracheal intubation in 202 patients with COVID-19 in Wuhan, China: lessons learnt and international expert recommendations. Br J Anaesth 2020;125(1):e28-e37

4 Malhotra Kapoor P. COVID-19 thrombosis: an unsolved mystery. J Card Crit Care TSS 2020;04(01):01-04

5 Garg R. Resilience in the Bhagavad Gita: a discourse analysis. Int J Emerg Ment Health 2019;21:10.4172/1522-4821-C1-027

6 Kapoor PM. Women in covid-19 pandemic: influential leadership is the need of the hour. Ind J Car Dis Wom 2020;5(3):271-273 